\title{
THE CHOICE AND EFFECT OF MODE OF TRANSPORTATION IN THE FLOW OF AGRICULTURAL FOOD STUFF IN RURAL URBAN FLOW: A CASE STUDY OF ZARIA AREA.
}

By

\author{
FOIN, DAVID NCHOUJI \\ Department of geography \\ A.B.U. Zaria.
}

\begin{abstract}
The study determined the choice and effect of modes of transportation in rural-urban flow of Agricultural food products to Zaria urban center. The primary data were obtained for the investigation using a structured sets of questionnaire. Descriptive statistics and regression analysis were used for the investigation. The results showed that cereal crops constitute the main grains in the area for sale. The specialization in the supply of food stuff to Zaria town conforms to Von Thunen's model of concentric. Zonation. Perishable and less bulky market garden products are supplied from areas immediately surrounding the urban area while others come from location of $16 \mathrm{~km}$ and above. The study further showed that the most single means of transportation used to transport food grains to Zaria town is motor vehicle and closely followed by motor cycle. These means of transportation are used in combination with one or the other with one being dominant at one location. Also the distance of location from Zaria town appears to be the single most important factor affecting the use of one or the other means of available transportation system. It was observed that some means of transportation are rejected at certain points (locations) because of the degree of risk. Base on this finding, the following recommendations are put forward. That urban planners should identify the pre-urban critical thresholds over which motor vehicle transport is not enough so as to extend more town city motor vehicle services to move food stuff to Zaria Town. That town planners who exist separately from rural development planners should be replaced by a common central planning authority which can handle as a united issue all aspects of development planning, including transportation, both in the urban and rural areas.
\end{abstract}

\section{INTRODUCTION}

Nigeria has an expanding urban population which is making ever greater demands on agricultural production and marketing system. The expansion of urban demand for food stuffs has stimulated the direct sales to urban consumers by some rural producers. The network of market places connected by flow of commodities, traders and rural producers/sellers, shapes the area system within which the rural economy functions.

One very impressive and also problematic feature of population distribution within Nigeria in particular since the 1980s is the rapid growth in the number, size and population of urban centre. The bulk of economic enterprise, political activity, social and intellectual life of the country is already centered in the towns and cities. So great has been the urbanization movement that many of the centres have come to contain more inhabitants than they can adequately support or regularly employed (Steel, 1961). The country at present is said to be over urbanized, viewed against the incompatibility of its level of urbanization and stage of economic development (Mabogunje, 1968).

Nigerian urban inhabitants so large as they are, and like their counterpart in many places (Dickinson, 1947) depend mostly, if not entirely, on farmers in the rural areas for their requirements of agricultural food products. The towns therefore constitute best-price markets for rural agricultural products and the farmers are keen to benefit from the situation. This arises the necessity for and inevitability of flow of agricultural food products from the rural areas to urban centres, which is a common feature and fundamental aspect of the day-to-today functioning of the urban-rural system. The 
functional economic regions of Nigeria can be pictured as a set in such urban-rural or periphery systems of varying hierarchies across space. The efficiency of the agricultural produce flow depends very much on the transport facilities available and in use. Transport constrains arise for the different locations from:

i. The absence of certain transport modes or intramodal types so that there is limited or no choice of medium of transportation.

ii. The inefficiency of the means commonly used; and

iii. The poor conditions of the surface over which the traffic flows.

\section{Objective of the Study:}

This study attempted to identify the means of transportation available and are used dominantly at different locations within the Zaria peripheral region to move agricultural foodstuff to the town. It is also to evaluate these means in items of their operational efficiency. The spatial pattern of dominance and efficiency levels of the means of transportation was established and some prescriptive suggestions were made towards effective planning of transportation of food crops from the rural areas to the towns. 


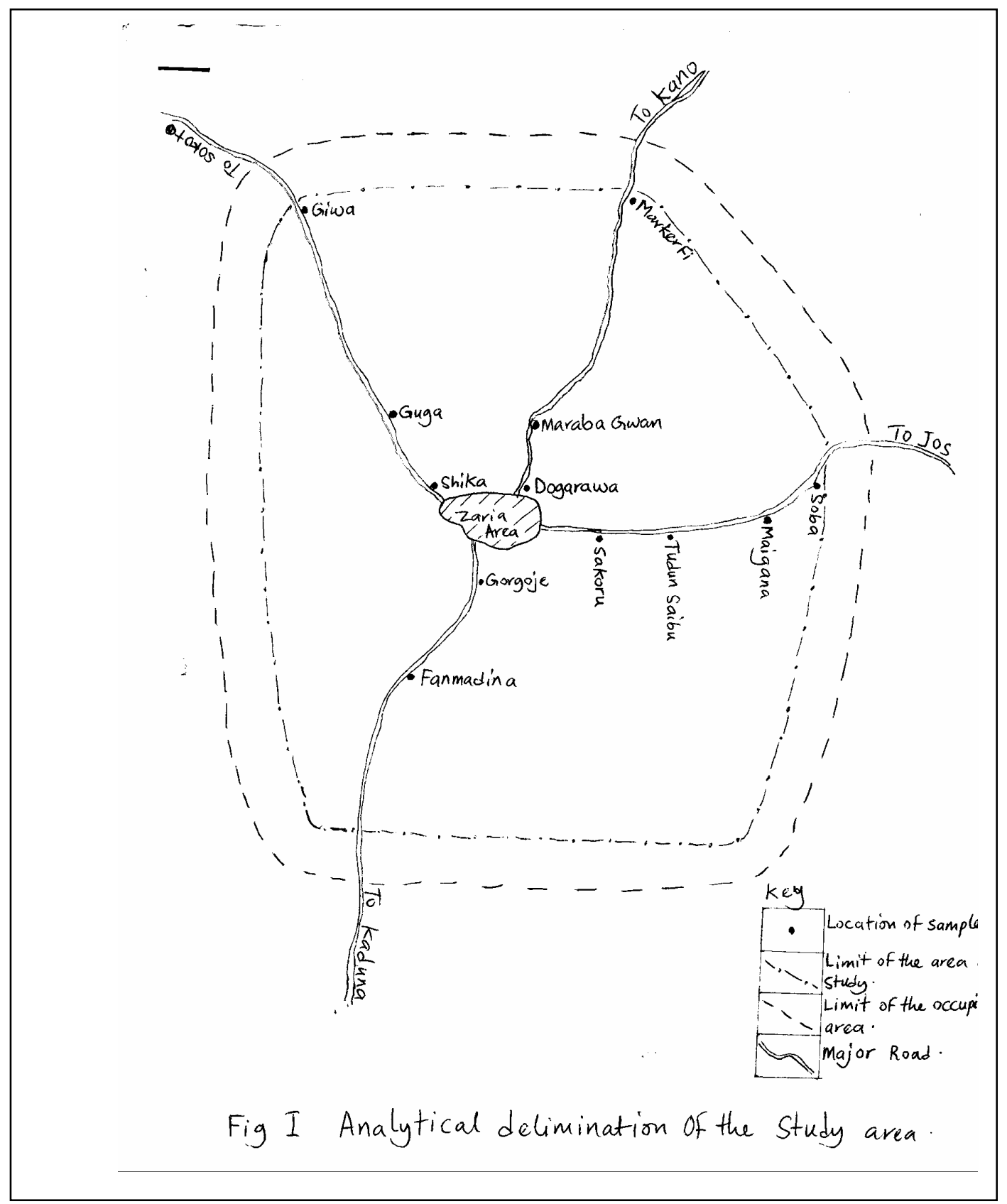

The control area for the study include Sabon Gari, Samaru and Zaria City, the capital for the old Zaria region, at the centre and the surrounding rural areas that would normally sell their surplus agricultural product directly at the Zaria town.

The Zaria area where the study is limited to has an average radius of about $50 \mathrm{~km}$ and together with the centre enclose about $2500 \mathrm{~km}$. The limit of the upland in each direction is based on degree of association of the sampled settlement with Zaria as an urban market for agricultural produce. The degree is associated as a ratio of respondents who sell their produce in Zaria town to the total number of sampled at the location. Fifty percent forms the divide between settlements that belong to the limited area of study and those outside it.

PRIMARY DATA ANALYSIS 
The primary data were obtained using a well structured questionnaire. A total of 240 farmers/traders were randomly selected from 12 location in Zaria region where they transport food grains to Zaria town for sale. The tool used to analyzed the study are cross tabulation analysis and regression analysis. Zaria urban area has grown tremendously over the last four decades particularly from the 1990s. . In 1952 the population was 58,000 inhabitance by 1963 population had raise to 110,000 people (Zaria and its region) by 1991, the population has raised to 508,385 (NPC, 1991) and it is currently estimated that 737158 people live within the statutory limits of the town.

Zaria town houses the military headquarters for the training of Nigeria army, a polytechnic, Ahmadu Bello university, Nigeria College of Aviation Technology, two Chemical research institutes, National Institute of Transport Technology (NITT) and the recently expanded institute of health, Ahmadu Bello University. Thus, with this added status, Zaria constitute a rapidly growing and dense populated town; a very effective market for food crop produces. Consequently, such a large urban area can have a very important effect upon the neigbouring rural communities. It offers a great opportunities to them for marketing food crops. The two major demands that Zaria town makes upon the near by country side are fuel and food; the later is almost of particular interest. Some of the crops produced like maize, guinea corn, beans, and rice are for sale as well as for local consumption. However others produced like groundnut, onion, Soya beans, pepper and millet are almost entirely for sale with very little consumed locally and more than half taken to the town for sale (Foin, 2001). Cereal crops which constitute the main grains in the area for sale, are grown in the rainy season. Vegetables are grown through both irrigation and rainfed and therefore are available throughout the year.

\section{RESULT AND DISCUSSION}

The feature of agricultural economy introduce a wide diversity of the nature of agricultural produce available at different locations in the villages to be transported to the town and also the means of transportation used. There is however a measure of regional specialization of dominant produce which different areas take to the town using the dominant means of transportation.

Types and spatial pattern of food-crops supplied to Zaria.
Food products commonly supplied to Zaria by the areas umland farmers include green vegetables, tomatoes, okro, fruits, maize, guinea corn sweat potatoes, yams, onion, beans, rice, millet, soya beans and sugar care.

Basic foodstuff like yams, gari, banana, plantains, pineapples, oranges come from outside the umland.

Field investigation shows that a real specialization in the supply of the products conforms largely with Von. Thunen's model of concentric zonation of agricultural production on the basis of crop types towards the end of keeping economic (mainly location) rent as high as possible (Chisholu, 1962). The easily perishable and less bulky market garden products such as tomatoes, okro, green vegetables tomatoes and fruits are supplied mainly from areas immediately surrounding the town with the range of $0-7 \mathrm{kms}$ and sometimes above seasonally.

Most crops like rice, soya beans, Irish potatoes , maize, guinea corn, sweat potatoes and yams come mostly from location of between $16 \mathrm{~km}$ to Zaria. That is, the outermost zone of the umland. This seems to suggest that the bulkiest of all the agricultural foodstuffs supplied among other come to Zaria town from outside the zone. This looks like the anti-thune's model. However, outside the prei-urban region where market gardening is practiced because of serious shortage in agricultural land, it is the most profitable line of production. Marketing surplus as are planned and got from crops that naturally give the highest yield in the area. The means of transporting the produce to the town is a subordinate consideration. Hence movement of food crops come against a number of constraints.

Crops like tomatoes, okro, vegetable fresh maize, onion and sweet potatoes are more diffused in their source of supply. They can be produce almost every where especially outside the peri-urban zone. In effect, crops like sweet potatoes, onion and even tomatoes come to Zaria at times dominantly from a zone of production far away between 7 and $16 \mathrm{~km}$ or above from the town.

\section{MEANS OF TRANSPORTING FOODSTUFF AND THEIR RELATIVE MEANS OF IMPORTANCE.}

The available means of transporting the food products, are motor cycle, bicycles, haulage, head portage and motor vehicle. Head portage currently for the use of transporting food product is limited due to availability of other transport means. These are employed in 
combination at different locations with one type dominant for place of transportation others as subsidiary. The dominance of one particular medium is influenced mostly by factors such as:

i. Distance of the location from the town

ii. Nature of produce available for transportation

iii. Volume of produce

vi. medium. iv. Degree of risk which the farmer or the trader is associated with when using the medium.

v. The comparative favourableness of freight rate structure operating in the use of

the 
Samaru Journal of Information Studies Vol.6 (1 \& 2) 2006

Table 1 Available means of transportation and ratio of interviewed traders/farmers using each means at different location

\begin{tabular}{|c|c|c|c|c|c|c|c|c|c|c|}
\hline \multirow[t]{2}{*}{$\begin{array}{l}\text { S/ } \\
\text { No }\end{array}$} & \multirow[t]{2}{*}{ Village group } & \multirow[b]{2}{*}{$\begin{array}{l}\text { Basic } \\
\text { Control } \\
\text { sample }\end{array}$} & \multicolumn{2}{|c|}{ Motor vehicle } & \multicolumn{2}{|c|}{ Motor cycle } & \multicolumn{2}{|l|}{ Bicycle } & \multicolumn{2}{|c|}{$\begin{array}{l}\text { Head } \\
\text { porterage }\end{array}$} \\
\hline & & & $\begin{array}{l}\text { No. of } \\
\text { Respon- } \\
\text { dents }\end{array}$ & $\begin{array}{l}\text { \% of } \\
\text { Respon } \\
\text { dent }\end{array}$ & $\begin{array}{l}\text { No. of } \\
\text { respon } \\
\text { dents }\end{array}$ & $\begin{array}{l}\text { \% of } \\
\text { Respon } \\
\text { dents }\end{array}$ & $\begin{array}{l}\text { No. of } \\
\text { Respon } \\
\text { dents }\end{array}$ & $\begin{array}{l}\text { \% of } \\
\text { Respon } \\
\text { dents }\end{array}$ & $\begin{array}{l}\text { No. of } \\
\text { Respon } \\
\text { dents }\end{array}$ & $\begin{array}{l}\% \text { of } \\
\text { Respon } \\
\text { dents }\end{array}$ \\
\hline 1. & Dogorawa & 20 & 4 & 20 & 14 & 70 & 1 & 5 & 1 & 5 \\
\hline 2. & Maraba Gwanda & 20 & 16 & 80 & 3 & 15 & 1 & 5 & 0 & 0 \\
\hline 3 & Makarifi & 20 & 18 & 90 & 2 & 10 & 0 & 0 & 0 & 0 \\
\hline 4 & Shika & 20 & 14 & 70 & 4 & 20 & 2 & 10 & 0 & 0 \\
\hline 5 & Guga & 20 & 18 & 90 & 2 & 10 & 0 & 0 & 0 & 0 \\
\hline 6 & Giwa & 20 & 20 & 100 & 0 & 0 & 0 & 0 & 0 & 0 \\
\hline 7 & Sakaru & 20 & 4 & 20 & 13 & 65 & 3 & 15 & 0 & 0 \\
\hline 8 & Tudun Saibu & 20 & 18 & 90 & 2 & 10 & 0 & 0 & 0 & 0 \\
\hline 9 & Maigana & 20 & 19 & 95 & 1 & 5 & 0 & 0 & 0 & 0 \\
\hline 10 & Soba & 20 & 20 & 100 & 0 & 0 & 0 & 0 & 0 & 0 \\
\hline 11 & Gogoroji & 20 & 6 & 30 & 10 & 50 & 3 & 15 & 1 & 5 \\
\hline \multirow[t]{2}{*}{12} & Fanmadina & 20 & 7 & 35 & 10 & 50 & 2 & 10 & 1 & 5 \\
\hline & & 240 & 104 & $\begin{array}{l}820 \\
\text { average } \\
68.3\end{array}$ & 61 & $\begin{array}{l}305 \text { average } \\
25.4\end{array}$ & 12 & 6 average 5 & 3 & $\begin{array}{l}\text { Average } \\
1.6\end{array}$ \\
\hline
\end{tabular}

Sources: Field Survey 2006. 
Table 1 shows the frequency of use of the different means of transportation at the locations sampled (as shown in fig 1). These location, are arranged in the table beginning with the village nearest to Zaria along Zaria-Kano Road and then moving clock wise to the others entering Zaria town.

The use of motor vehicle from the table is seen to be the most important and popular means of transportation used to transport food stuff to Zaria town with 164 farmers/traders out of 240 using it. This is closely followed by motor cycle (61 out of 240 use it) and bicycle with 12 out of 240 using it. The use of head portage to convey foodstuff to the town is almost completely out of question as only 3 out of 240 farmers/traders reported that they use it.
Even though it is very clear from the table that the means of transportation are used in combination with one or the other and one usually being dominant at one location it can not be immediately explain what combination is this statistics base on for the places. To determine this, a standard deviation analysis of the combination is done for each place base on percentages of the farmers/trades using the different means. The combination which shows the least deviation from a theoretical based curve is seen as the basic combination.

Table 2. Available means of transportation and ratio of interviewed traders/farmers using each means at different location

\begin{tabular}{|l|l|l|l|l|l|l|l|l|l|l|}
\hline & $\begin{array}{l}\text { One } \\
\text { means }\end{array}$ & \multicolumn{3}{|l|}{ Two means } & \multicolumn{3}{l|}{ Three means } & \multicolumn{3}{l|}{ Four means } \\
\hline & Mv & Mv & Mc & Mv & Mc & Bc & Mv & Mc & Bc & Hp \\
\hline $\begin{array}{l}\text { \% of theoretical } \\
\text { based curve }\end{array}$ & 100 & 50 & 50 & 33.3 & 33.3 & 33.3 & 25 & 25 & 25 & 25 \\
\hline $\begin{array}{l}\text { \% of actually } \\
\text { observed }\end{array}$ & 80 & 80 & 15 & 80 & 15 & 5 & 80 & 15 & 80 & 0 \\
\hline Deviation (d) & 20 & 30 & 35 & 46.7 & 18.3 & 28.3 & 55 & 10 & 55 & 25 \\
\hline D2 & 400 & 900 & 1225 & 2180.89 & 33489 & 800.89 & 30.25 & 100 & 30.25 & 625 \\
\hline$\Sigma \mathrm{d} 2$ & 400 & $\mathbf{2 1 2 5}$ & & 36470.78 & & & $\mathbf{6 7 7 5}$ & & & \\
\hline$\Sigma \mathrm{d} 32 / \mathrm{n}$ & 900 & & & & & & & & & \\
\hline
\end{tabular}

Table 2 above is an example of the analysis for the second village on table 1 . In order to assess whether motor vehicle is the most important and popular means of transport at that location, two media combination of motor vehicle and motor cycle, three media of motor vehicle, motor cycle and bicycle were assessed. The analysis in table 2 shows that motor vehicle and bicycle with deviation 2125 is statistically the basic combination for Maraba
Gwanda. Table 3 is the summary of the situation for all the locations sampled relative to dominance of the various transportation combination is shown.
a. $\quad \mathrm{MV}+\mathrm{MC}+\mathrm{B}+\mathrm{H}=3$ location
b. $\mathrm{MV}+\mathrm{MC}+\mathrm{B}=3$ location
c. $\mathrm{MV}+\mathrm{MC}=4$ location
d. $M V=2$ locations
Total $\quad 12$ 
Table 3 Summary of the statistically basic combination of means of transportation at the different location.

\begin{tabular}{|c|c|}
\hline 1. Dogorawa & $\mathrm{MV}+\mathrm{MC}+\mathrm{BC}+\mathrm{HP}$ \\
\hline 2. Maraba Gwanda & $\mathrm{MV}+\mathrm{MC}+\mathrm{BC}$ \\
\hline 3. Makerifi & $\mathrm{MV}+\mathrm{MC}$ \\
\hline 4. Shika & $\mathrm{MV}+\mathrm{MC}+\mathrm{BC}$ \\
\hline 5. Guga & $\mathrm{MV}+\mathrm{MC}$ \\
\hline 6. Giwa & MV \\
\hline 7. Sakaru & $\mathrm{MV}+\mathrm{MC}+\mathrm{BC}$ \\
\hline 8. Tundun Saibu & $\mathrm{MV}+\mathrm{MC}$ \\
\hline 9. Maigana & $\mathrm{MV}+\mathrm{MC}$ \\
\hline 10. Soba & MV \\
\hline 11. Gwogwaje & $\mathrm{MC}+\mathrm{MV}+\mathrm{BC}+\mathrm{HP}$ \\
\hline 12. Fanmadina & $\mathrm{MV}+\mathrm{MC}+\mathrm{BC}+\mathrm{HP}$ \\
\hline
\end{tabular}

Here and similar tables

MV = Motor Vehicle

MC $=$ Motor Cycle

$\mathrm{BC}=$ Bicycle

HP $=$ Head Portage

The aggregate intensity over the area of each of the single mans of transportation could further be reckoned with. The aggregate intensity of a particular medium is based on how often it ranks as first, second or third in used with the basic combination in which it occurs.

The ranks are weighted in a ratio of 3:2:1 in accordance as they are first, second or third in the relevant combination. It is therefore important to observe in this regard that the maximum number of the means of transportation that take place in any one of the combination is three and in this case excluding head portage. At any of the locations where a particular medium is used (now that head portage is excluded) it does not appear in the combination and the medium is therefore accorded (0) for the purpose of computing the overall weigh relatively.

By multiplying each rank by the number of occasions, every one media could be established. This will give a picture of aggregate intensity of the use of the various means of transportation means of food-crops as shown in table 4 and further illustrated by the graph in Fig 3. The calculation revealed that the use of motor vehicle is 53\% over the entire settled area of Zaria town. The use of motor cycle is $47 \%$ and bicycle is $0 \%$

Table 4: Aggregate Dominance of each different means of transportation

\begin{tabular}{|l|l|l|l|}
\hline & Motor vehicle & Motor cycle & Bicycle \\
\hline $\begin{array}{l}\text { a. Frequency of ranking first (out of 12 location) x } \\
\text { weight of rank (3) }\end{array}$ & $8 \times 3=24$ & $4 x 3=12$ & 0 \\
\hline $\begin{array}{l}\text { b. frequency of ranking second (out of 12 location) } \\
\text { x weight of rank (2) }\end{array}$ & $2 \times 3=6$ & $5 \times 3=15$ & 0 \\
\hline $\begin{array}{l}\text { c. frequency of ranking third (out of 12 location) x } \\
\text { weight of rank (1) }\end{array}$ & 0 & 0 & 0 \\
\hline d. Frequency of not appearing (out of 12 location) x & 0 & 0 & 0 \\
\hline
\end{tabular}




\begin{tabular}{|l|l|l|l|}
\hline weight of rank (0). & & & \\
\hline e. Aggregate weight and means of transport & $30(57 \%)$ & $27(57 \%)$ & $0(57 \%)$ \\
\hline f. Percent of overall weight & $53 \%$ & $47 \%$ & $0 . \%$ \\
\hline
\end{tabular}

\section{EFFICIENCY OF TRANSPORTATION}

Because of the vital importance of the level and pattern of transport resources to economic development (Hoyle, 1993) there is every justification to show concern for the type of transportation system used as so far analyses by which agricultural food producers are supplied to Zaria town from the umland. The system to say the least is efficient.

Motor vehicle and motor cycle together exert 100 ?\% dominance in the system. Motor vehicle have a high haulage capacity and speed of movement to adequately meet the demands of urban market of Zaria town. This is because the formers/traders carry large quantities of agricultural produce to the urban market for sale using motor cars.

The use of motor vehicle is dominant over areas where food crop like maize, guinea corn, soya beans, cowpea, rice, pepper come to the town and also from the nearby rural local periodic markets which serve as sources of supply of food corps to the urban area. .

The use of motor vehicle, is a relatively more efficient means of transportation in consideration of the speed and haulage capacity. Motor vehicle has 53\% aggregate dominance in the area. This medium of transportation is also confined mostly to the outer zone of the production fields which offers to the Zaria town the large volume and variety of products. The nearest reach of the zone to Zaria town is about $35 \mathrm{~km}$, a situation which does not appear to represent the best economic use that can be made of motor vehicle transportation in the area.

\section{Factors affecting use of means of transportation.}

From the analysis, the factor affecting the use of the various means of transportation will, as a matter of convenience, be based on the first-ranking medium established for the different locations. These first rank media are still in most cases, much more frequently used than any other means with which they are combined.

Distance of the locations from Zaria town appears to be the singe most important factor affecting the use of one or the other of the available transportation media. Product moment correlation of distance of the location from Zaria town and the number of people from the samples taken who use particular medium in preference to any other at their location were made for (1) use of motor cycle which as dominant for locations nearest to Zaria and (2) use of motor vehicles which dominates for location furthest from Zaria town. The coefficient obtained for the first case is $\mathrm{r}=0.85$ and for the second case $\mathrm{r}+0.1 \%$ level.

From this, it could be strongly asserted that the more the distance from Zaria town, the less the use of motor cycle or the more the distinct from Zaria town the more the use of motor vehicle.

The regression analysis for the distribution in each case tend to suggest that the threshold of Zaria town based on the use of motor cycle terminates after $14 \mathrm{kms}$ from the town

It is however, quite costly to think that people can convey food crops conveniently to Zaria town over $14 \mathrm{kms}$ using motor cycles. The upper limit of convenient cost in distance to the town established during the survey is $5 \mathrm{~km}$. It is the gap in space between 5 and $14 \mathrm{kms}$ that is dominated by the use of motor vehicle.

The regression curve of patronage of motor vehicle based on distance from Zaria cuts the distance axis at the point of about 20.5 kilometers. The implication is that at this point and above, it is easy and possible for the people to catch a motor vehicle to convey their food products to the town. Actually, the absolute value of 20.5 kilometers is not quite important to the analysis but this situation exemplifies a common one where almost all the locations, have motor vehicle transporters operating from, and some quite dose to the town and fall within the town's normal taxi-service range and too near to be served by motor vehicle transportation passing them to the town. What should be suggested immediately here is that town planners should identify such location that are very close to the town with a view of discouraging motor vehicle services so as to reduce traffic congestion within the town, extend and improve the services of city buses and taxi cabs to such locations.

It must be appreciated however that in some cases distance may not be the critical factor in determining the types and means of transportation which is used. Though related to distance is the nature and volume of produce to be transported. The freight rate, time and the degree of risk the farmers/traders is associated with when using anyone of the available transportation media have been found, simply or in combination, to be the decisive 
factor for some locations in using a means of transportation.

Market garden products which are usually taken to the town by motor cycle, and bicycle are highly perishable commodities and should be made available in the motor hours. .

Lastly, it was observed that some means of transportation are rejected at certain point (locations) because of the relative degrees of risk the people associate with using them as compared to the one which is preferred. The analysis undertaken in this regard showed that bicycle and motor cycle were assessed some what more risky than motor vehicle transportation and head porterage as the least risky. This is quite understandable because it is common sight in people's day to day experiences of cyclists knocked down by motor vehicles. This is enough to engender a feeling that the use of motor cycles as a means of transportation is more risky than motor vehicle in terms cost to life.

\section{CONCLUDING REMARKES}

1. Arising from the above, it is recommended that: Uban planners in Zaria should identify the peri-urban critical thresholds over which motor vehicle transport is not enough so as to extend more town city motor vehicles to facilitate removal of agricultural food crops to the city.

2. Urban and rural development policy makers within the central periphery system in Zaria area to cooperate in mutually beneficial transport development project

3. Town planners who today exist separately from rural development planners should be replaced by a common central planning authority that can handle as a united issue all aspects of development planning, including transportation, both in the urban and rural areas.

The flow of Agricultural products from rural areas to urban centers in Nigeria is very crucial as seen in the case study of Zaria umland agricultural region. This flow is important to meet the ever increasing demand of urban population expansion and also for the organic economy of the existing urban centers and also for the growing disparity between urbanization and the people's capability to feed themselves.

\section{REFERENCES}

Peter, O. S.A. (1998): Comprehensive Geography for Secondary Schools (A Johnson Publishers Ltd.

Hussain, B. I. (1990): Food Grain marketing on farm income in Ikara and Zaria, M.Sc. Thesis, Dept. of Geography ABU.

A. M. Daramala, et al. (1999): Exam focus Agricultural Science for WASSCE and JME University Press Plc. Ibadan.

Chisholm, M. M. (1962): rural settlement and land use, London.

Dickson, R. E. (1947): City region and regionalism London.

Ekeocha, I. A. 91973): The Relative Importance of the Modes of Freight Transportation in Owerri Area, Unpublished B. A. thesis Dept of Geography University of Nigeria Nsukka.

Foin, D. N. (2001): Effects of Road transport network on agricultural produce marketing in Giwa LGA: MSc. Theses, Dept of Geography A.B.U

Mortimore, M. J. (1970): Zaria and its Regions, Depart. Of Geography; A.B.U. Publication

Gautehr, H. L. (1973): “Geography, Transportation and Regional Development” in Hogle, B. S. (ed) (1973), Transportation and development Macmillan, London. Pp. 19-31.

Hoyle, B. S. (ed) (1973): Transport and development Macmillan, London.

Mabogurje, A. L. (1968) urbanization in Nigeria, University of London Press.

Munby, D. (1968): Transportation, Penguin, Hammondsworth.

Reichman, S. (1973): “Transportation urban development in West Africa” in Hoyle, B. S. (ed) Op, cit; pp. 190-207.

Steel, R. W. (1961) :The towns of tropical Africa” in Barbour, K. M. and Prothero R.. M. Eassys on Africa population, routledge and Kegan Paul, London, pp. 249-278.

Weaver, J. C. (1954) "Crop Combination Regions in the Middle West” Regiew, vo. 44. pp. 175 - 200. 